\title{
Analysis of Power Switching Losses Accounting Probe Modeling
}

\author{
Kaiçar Ammous, Hervé Morel, Student Member, IEEE, and Anis Ammous
}

\begin{abstract}
This paper focuses on the errors affecting the estimation of power switching losses in power semiconductor devices based on integration of the voltage by current product. It is shown that the measured waveforms are not simply delayed by the probes, but some overshoots and distortions are due to the probes, which may not easily be corrected. These effects are the source of errors, particularly in fast transients. This paper shows analyses of simulation and measurements, including probe models.
\end{abstract}

Index Terms-Distortions, losses, measurement, power, probe modeling.

\section{INTRODUCTION}

$\mathbf{O}$ NE CLASSICAL approach for the estimation of switching losses in a power semiconductor device is based on the calculation of the power signal as the product of the current by the voltage signals. Then, the power signal is integrated. For medium power range devices, the transients may occur in some tens of nanoseconds. Recent papers [1], [2] have addressed the measurement of semiconductor device losses and focused on the limitations of digital oscilloscopes and their calibration with respect to high-speed waveforms. Other papers addressed the power loss measurement in the case of microwave power amplifiers [3], [4], where the power amplifiers are integrated circuits for which probes cannot be inserted. The present problem of loss measurements is then different. Current and voltage probes are inserted inside the circuit and connected to an oscilloscope.

To avoid boundary effect perturbations, a good practice is to measure signals on a device connected near the ground of the circuit or any other constant potential of the circuit.

As the frequency bandwidth is a key parameter in such a measurement system, it is assumed that the current and voltage probes, as well as the oscilloscope, have a sufficient bandwidth. Moreover, the probe is considered linear.

Application notes [5]-[8] point out that the instrumentation system should exceed this bandwidth by a factor of 3 .

This paper presents the analysis of probe effects on waveform measurements of a diode component during fast switching phases.

Manuscript received November 20, 2009; revised February 22, 2010; accepted February 23, 2010. Date of publication September 2, 2010; date of current version November 10, 2010.

K. Ammous and A. Ammous are with the Groupe de Recherche, Power Electronic Group, Département de Génie Electrique, Ecole Nationale d'Ingénieurs de Sfax, 3038 Sfax, Tunisia (e-mail: ammous_kaissar@yahoo.fr; anis.ammous@enis.rnu.tn).

H. Morel is with the Universite de Lyon, INSA-Lyon, Lab. AMPERE, CNRS \#5005, 69621 Villeurbanne, France.

Color versions of one or more of the figures in this paper are available online at http://ieeexplore.iee.org.

Digital Object Identifier 10.1109/TIM.2010.2047302
This paper also focuses on probe modeling and compares simulation results with measurement results on a switching cell.

Following the introduction, this paper is organized in three additional sections. Section II presents probe and cable length effects on signal delays in a simple test circuit. Section III introduces refined models of the probes and describes a test circuit (a switching cell) that is used to measure the current and voltage waveforms of a power diode device under test (DUT) to illustrate how the probes affect the waveform measurements. Section IV presents results on power diode turnoff.

\section{Test Circuit to Estimate Delay}

The simple test circuit in Fig. 1 is considered to show the delay introduced by the current and voltage probes. Capacitor $C$ is used to supply to transient currents, and the current source includes a serial self-inductor to avoid transient voltages. $V_{R}$ is a voltage source, and $I_{F}$ is a current source.

It appears that synchronicity between waveforms is of prime importance (Figs. 1 and 2). Application notes [8] indicate that a delay correction is required, which may even be treated by high-quality oscilloscopes as a simple time skew (namely, the deskewing process). The delay depends on probe and cable lengths. A TMS-Research 1.2-GHz shunt [9] was used as the current probe, and a Tektronix P6139A 500-MHz voltage probe was considered. In Fig. 1, an IRF740 MOSFET transistor creates a current step waveform inside a $50-\Omega$ MP930 high-frequency resistor. Fig. 2 shows the current and voltage waveforms. A 3-ns delay may be estimated for $1 \mathrm{~m}$ of cable for both probes. However, Section III will show that a correction of the latter delay between current and voltage waveforms is not sufficient to guarantee an accurate estimation of power losses.

Fig. 3 shows the current waveforms during switching phases obtained by different types of current probes at turnoff of a diode DUT. Each current waveform case corresponds to a shunt connected with a given type of cable. Two types of cables were used, namely, coaxial (with two different lengths) and rigid coaxial copper cables. Measurements show that the copper cable gives the lowest overshoots and, thus, a more accurate current waveform.

Interactions also occur, and a good calibration of probes is required. Fig. 4 shows the classical equivalent circuit representing the interaction between a voltage probe and an oscilloscope. The cable is considered as ideal. In the case of semiconductor devices of medium current range (1-30 A), the OFF-state capacitance of the DUT is of the same order of magnitude as the voltage probe input capacitance $\left(C_{t} \approx C_{s}=8 \mathrm{pF}\right.$, equivalent 


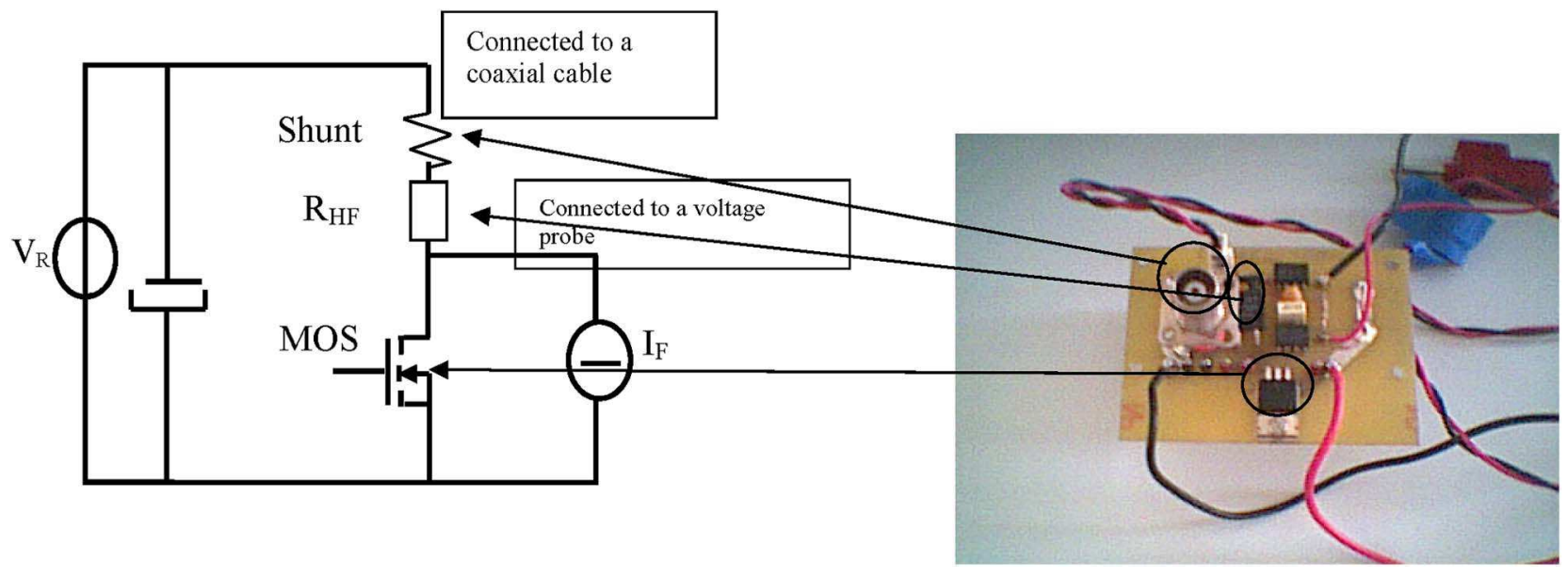

Fig. 1. Picture and schematic of the circuit used to estimate a delay between a voltage probe and a current probe (using a coaxial wire and a shunt). Capacitor $C$ is used to supply to transient currents, and the current source includes a serial self-inductor to avoid transient voltages. $V_{R}$ is a voltage source, and $I_{F}$ is a current source.

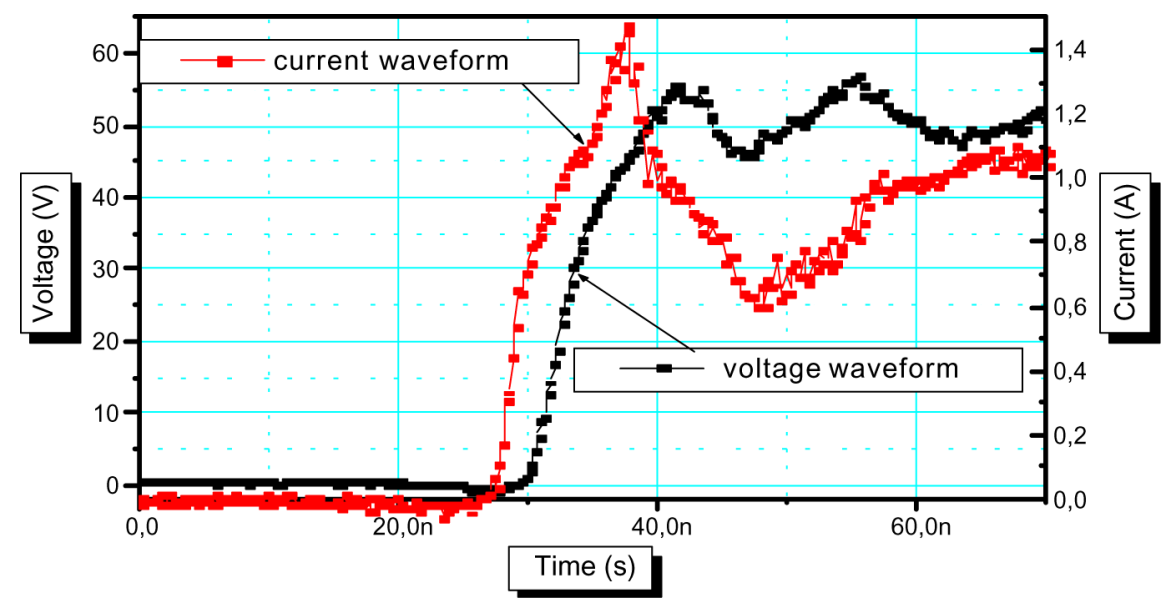

Fig. 2. Current and voltage measurement waveforms used in the proposed test circuit (of Fig. 1).

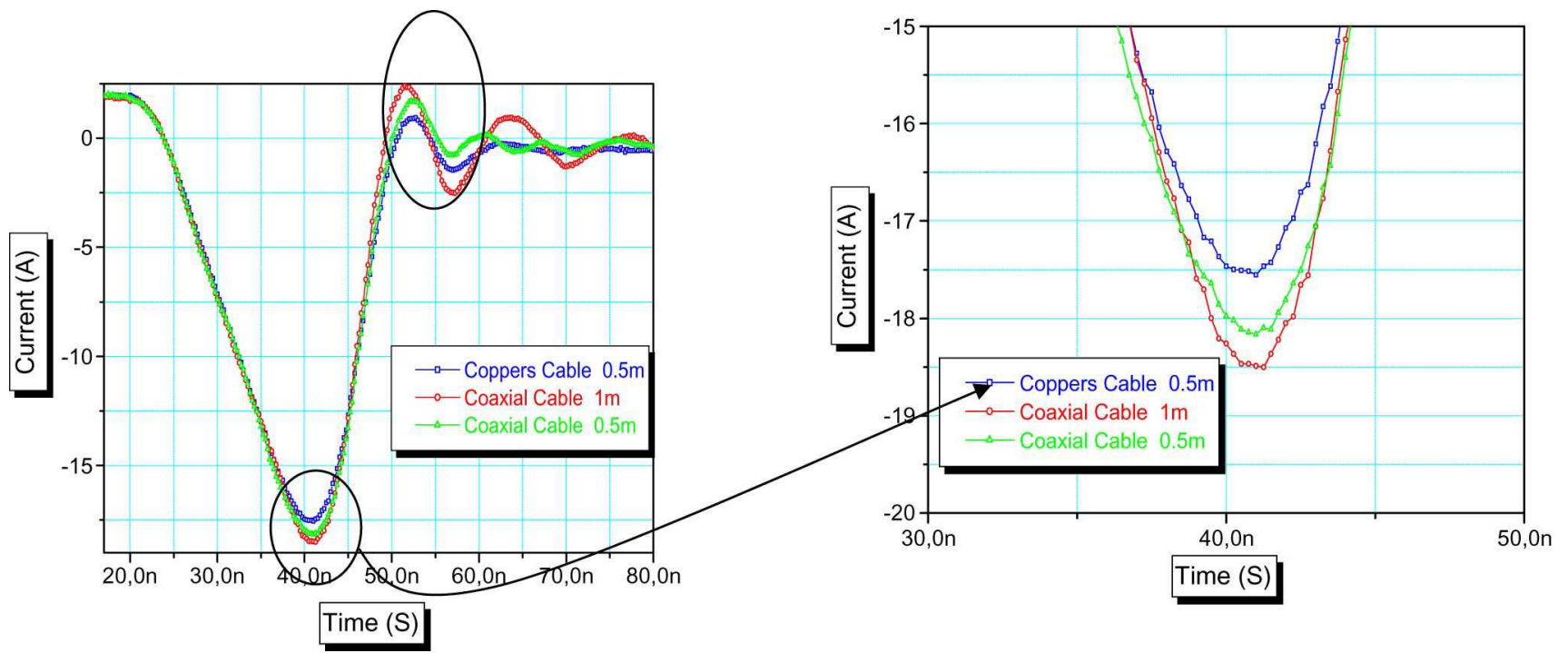

Fig. 3. Diode current measurement waveforms obtained with the different current probes at turnoff.

to the junction capacitance of a power diode). The effects of the voltage probe capacitance are qualitatively discussed in [10]. Tektronix publishes [10] on how the voltage probe input ca- pacitance affects the risetime and the delay at the output of a usefulness circuit (Table I). For another quantification of probe effects, turnoff switching is simulated with a capacitance 




Fig. 4. Classical equivalent circuit representing the probe and the oscilloscope input.

TABLE I

MEASUREMENT ERRor INTRODUCED INTO A CiRCUIT OUtPut Signal B THE InPUt CAPACitANCE of the Probe

\begin{tabular}{ccccl}
\hline $\begin{array}{c}\text { Probe Input } \\
\text { Capacitance }\end{array}$ & Rocthr & $\Delta \mathbf{p d}_{\mathrm{d}}$ & $\begin{array}{c}\text { Measurement } \\
\text { Error in \% }\end{array}$ & Probe Type \\
\hline \hline $0.15 \mathrm{pF}$ & 0.025 & $9 \mathrm{psec}$ & 3 & Tektronix P6150 Probe \\
\hline $0.4 \mathrm{pF}$ & 0.07 & $24 \mathrm{psec}$ & 8 & Tektronix P6207/P6217 Active FET Probes \\
\hline $0.6 \mathrm{pF}$ & 0.10 & $45 \mathrm{psec}$ & 15 & HP 54701A Active Probe \\
\hline $1.0 \mathrm{pF}$ & 0.17 & $51 \mathrm{psec}$ & 17 & Tektronix P6156 Zo Probe \\
\hline $1.0 \mathrm{pF}$ & 0.17 & $51 \mathrm{psec}$ & 17 & Tektronix P6243/P6245 Probe \\
\hline $2.0 \mathrm{pF}$ & 0.33 & $105 \mathrm{psec}$ & 35 & Tektronix P6205 FET Probe \\
\hline $3.0 \mathrm{pF}$ & 0.50 & $120 \mathrm{psec}$ & 40 & Tektronix P6201 FET Probe (1X) \\
\hline $8.0 \mathrm{pF}$ & 1.33 & $300 \mathrm{psec}$ & 100 & Tektronix P6139A Passive Probe \\
\hline
\end{tabular}

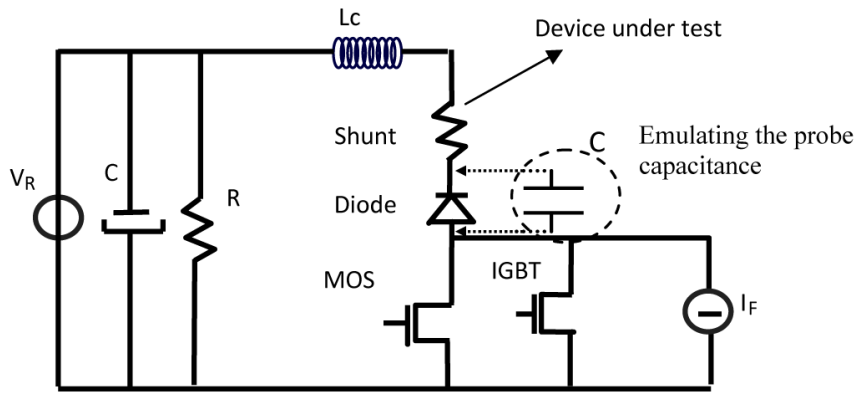

Fig. 5. Circuit used to simulate the diode under test behavior and the effect of the probe on current and voltage waveforms.

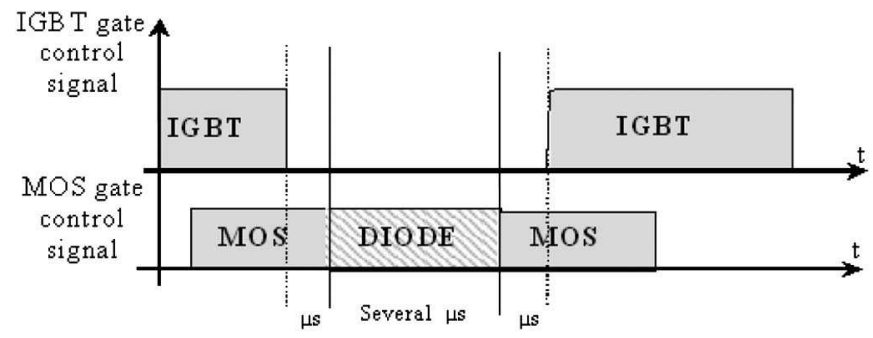

Fig. 6. Driving signals of the IGBT and the MOSFET used in the proposed test circuit (of Fig. 5).

connecting in parallel with a diode DUT (Fig. 5). Driving signals of the insulated gate bipolar transistor (IGBT) and the MOSFET used in the proposed test circuit (Fig. 5) are shown in Fig. 6. Capacitor $C$ represents the input capacitance of the probes device. Fig. 7 pictures how capacitor $C$ affects these
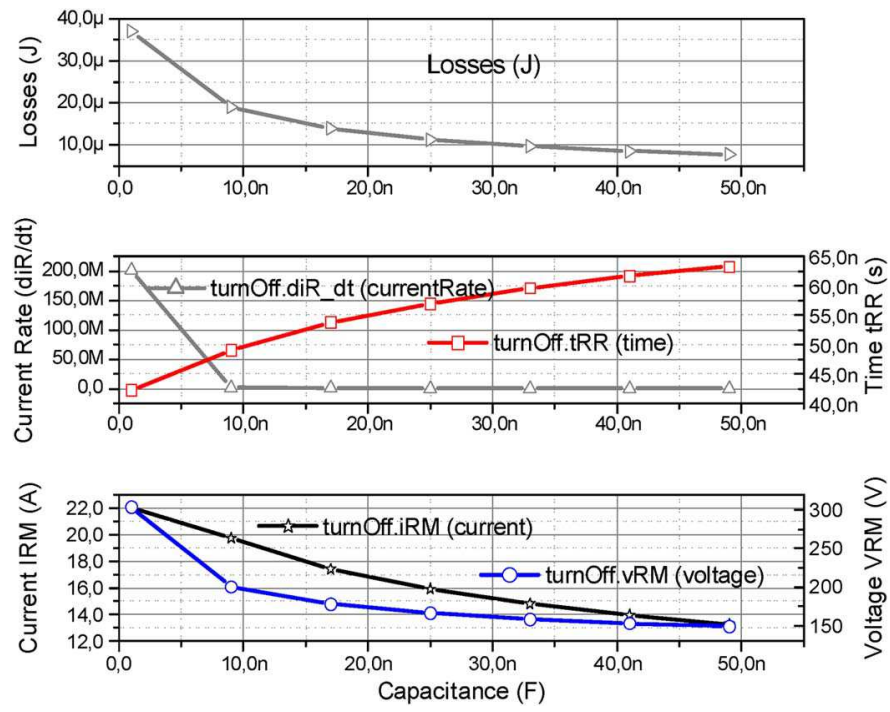

Fig. 7. Effect of the equivalent capacitance of the probe on diode current and voltage parameters during turnoff.

latter parameters and power loss estimations in the diode. To enlighten the errors in the estimation of power losses, one idea is to model the voltage and current probes and include these devices in the simulation process to improve the pertinence of the comparison between simulations and measurements. Often, in circuit simulations, the voltage probe is simply modeled as a simple equivalent circuit (Fig. 4), or it is not taken into account at all. Indeed, probe devices are more complex and may be described by the schematic in Fig. 8. It is well known that the voltage probe has to be calibrated to ensure a constant ratio between input and output voltages over a wide frequency range.

Nevertheless, even if adequately calibrated, a voltage or a current probe introduces distortion on the waveform.

The device simulator ISE [11] was considered with a classical 1-D p-i-n diode description, using technological parameters compatible with a $10 \mathrm{~A}-600 \mathrm{~V}$ device, as given in Table II. The maximum reverse voltage $V_{\mathrm{RM}}$, the maximum reverse current $I_{\mathrm{RM}}$, and current slopes $d I_{R} / d t$ and $d I_{F} / d t$ are parameters that characterize diode turnoff (Fig. 9). The following specifications could be estimated as acceptable for a medium-range power diode: $0-600 \mathrm{~V}, 500 \mathrm{MHz}$, and $C_{\text {input }}=0.1 \mathrm{pF}$. Unfortunately, efficient active voltage probes featuring adequate characteristics for power switching measurements do not exist. Thus, it is required to use passive voltage probes instead of differential active probes and to take into account the interaction.

\section{Switching Cell Modeling And Measurements}

To analyze the effects of the probe models, which are represented by a capacitance $C_{\text {probe }}$ in the circuit (Fig. 5), on power loss estimation, a switching cell is considered both for experiment and simulation. The power MOSFET transistor is modeled with the classical level-3 SPICE model [12]. The MOSFET parameters are given in Table III. A 1-D description of the p-i-n diode is developed with the device simulator ISE [11], combining the MOSFET model to simulate a switching cell. A switching cell wiring model is built using the software INCA [15] based on the partial-element equivalent circuit 


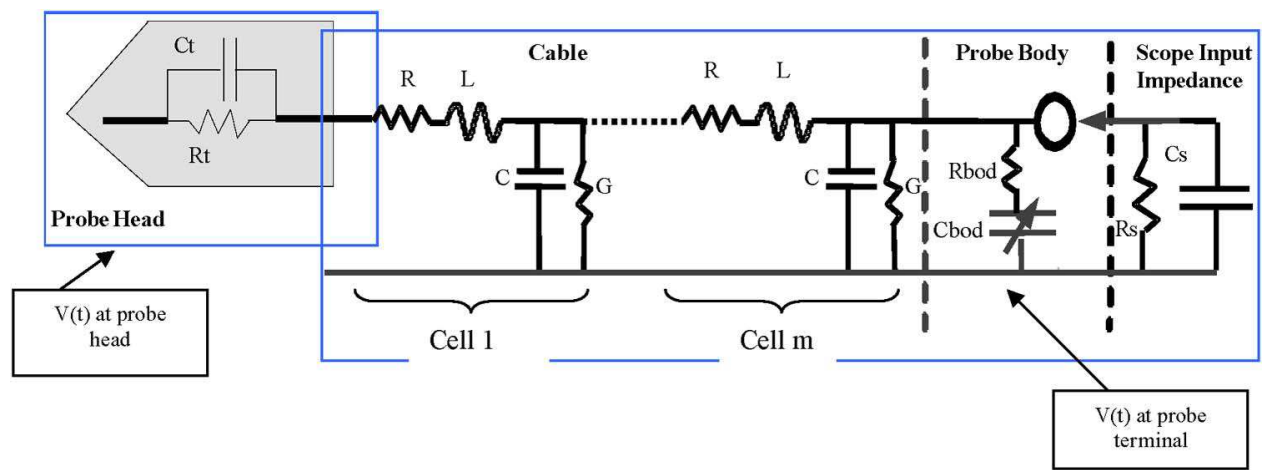

Fig. 8. Proposed model of the voltage probe: probe head model circuit $C_{t} R_{t}$, cable modeled by the sequence of line elements $(R, L, G, C)$, probe body represented by $R_{\text {bod }}$ and variable capacitance $C_{\mathrm{bod}}$, and scope input impedance model circuit $C_{s} R_{s}$.

TABLE II

Parameter Values Obtained by the Extraction Procedure for Diode and MOSFET Devices

\begin{tabular}{|l|c|c|c|c|}
\hline Parameters & $\begin{array}{c}\text { Ambipolar carrier } \\
\text { lifetime: } \tau(\mathrm{ns})\end{array}$ & $\begin{array}{c}\text { Effective area: A } \\
(\mathrm{mm} 2)\end{array}$ & $\begin{array}{c}\text { Doping } \\
\text { concentration : } \\
\mathrm{ND}(\mathrm{cm}-3)\end{array}$ & Width: W $(\mu \mathrm{m})$ \\
& & & 1.5 .1014 & 83 \\
\hline BYT12PI1000 & 258 & 5 & & \\
\hline
\end{tabular}

\begin{tabular}{|c|c|c|c|c|c|}
\hline Parameters & $\mathrm{V}_{\mathrm{T}}$ & $\mathrm{k}_{\text {plin }}\left(\mathrm{A} / \mathrm{V}^{2}\right)$ & $\mathrm{k}_{\mathrm{psat}}\left(\mathrm{A} / \mathrm{V}^{2}\right)$ & $\mathrm{R}_{\mathrm{DS}}$ & $\theta$ \\
\hline $\begin{array}{c}\text { MOSFET: } \\
\text { IRF740 }\end{array}$ & $3.77 \mathrm{~V}$ & 1.45 & 100 & $0.124 \Omega$ & 1.656 \\
\hline
\end{tabular}

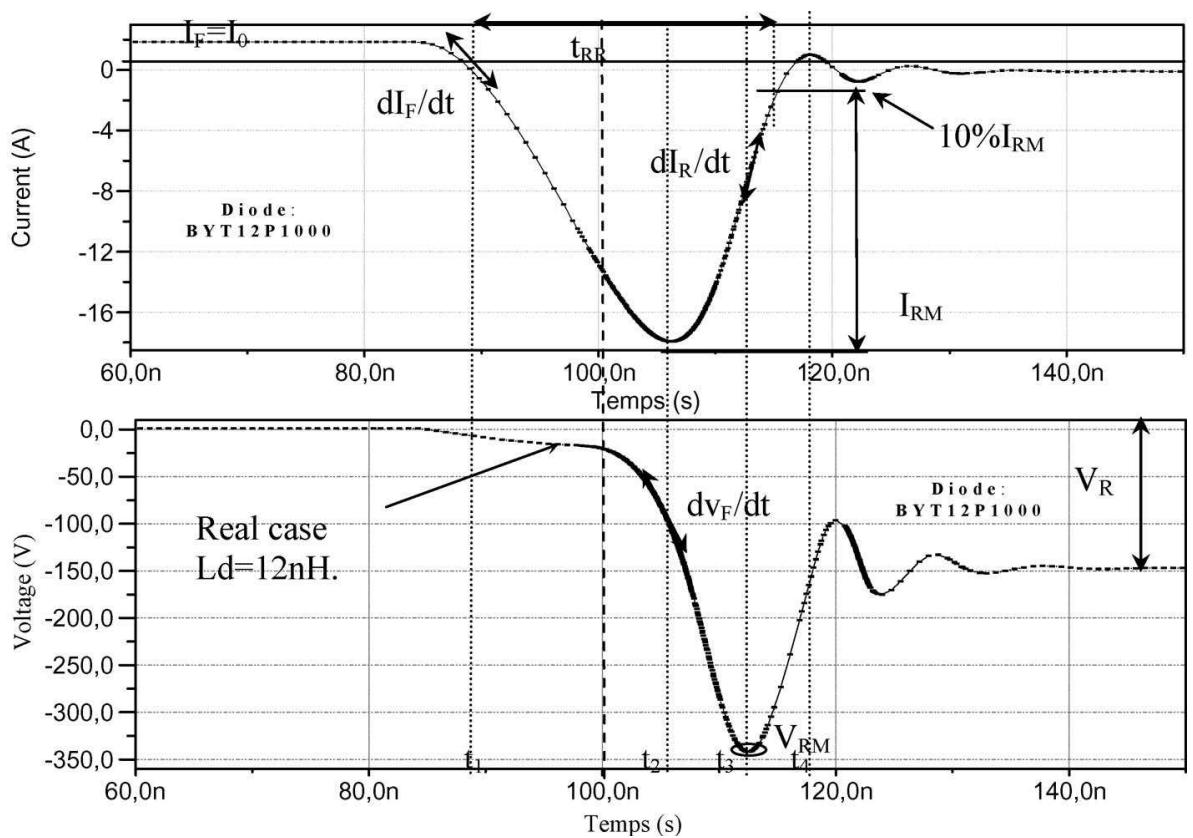

Fig. 9. Simulation waveforms of the voltage and the current evolution during turnoff [diode DUT BYT12PI1000, MOSFET IRF740, Lc $=90 \mathrm{nH}(\mathrm{parasitic}$ wire inductance), $I_{F}=2 \mathrm{~A}, V_{R}=150 \mathrm{~V}$, and $\left.T=300 \mathrm{~K}\right] . t_{1}$ is the time where the current reaches zero, $t_{2}$ is the time of the maximum current, $t_{3}$ is the time of the maximum voltage, and $t_{4}$ is the time where the voltage reaches $V_{R}$.

(PEEC) method [14]. The next section describes the circuit operating the switching cell under controlled conditions. The most stressing transient phase is definitely when the power $\mathrm{p}-\mathrm{i}-\mathrm{n}$ diode turns off. The power generated by the diode during turnoff is taken as an example for discussing the probe behavior and the interactions between the circuit and the probes.
The experimental setup is given in Fig. 5. It includes a switching cell (MOSFET transistor and $\mathrm{p}$-i-n diode), voltage $V_{R}$, and current $I_{F}$ dc supplies, but the control electronics is not shown. The MOSFET transistor (IRF740) ensures fast blocking of the diode current. The IGBT transistor (MUP304), which is slower but more robust than the MOSFET transistor, 
TABLE III

Parameter Values Obtained by the Extraction Procedure for Voltage and Current Probes

\begin{tabular}{|c|c|c|c|c|c|c|}
\hline Parameters & R1 & $\mathrm{C} 1$ & G1 & L1 & $\begin{array}{l}\mathrm{M}: \text { cells } \\
\text { number }\end{array}$ & $\begin{array}{c}\text { Models } \\
\text { Parameters at } \\
\text { Head or Body } \\
\text { Probe }\end{array}$ \\
\hline $\begin{array}{l}\text { Current Probe: } \\
\text { Coaxial wire }\end{array}$ & $0.0025 \mathrm{~m} \Omega$ & $100 \mathrm{pF}$ & $9 \mathrm{~ns}$ & $200 \mathrm{nH}$ & 6 & $\begin{array}{c}\text { Shunt model : } \\
\begin{array}{c}\mathrm{Rs}=25 \mathrm{~m} \Omega \\
\mathrm{Ls}=1 \mathrm{p} \mathrm{H} \\
\mathrm{Cs}=6.6 \mu \mathrm{F}\end{array}\end{array}$ \\
\hline $\begin{array}{l}\text { Voltage probe } \\
\text { P6139A } \\
\text { (TEKTRONIX) }\end{array}$ & $260 \Omega$ & $38 \mathrm{p} \mathrm{F}$ & $\begin{array}{c}1.5 n \\
S\end{array}$ & 540n H & 14 & $\begin{array}{l}\text {-Body probe } \\
\text { model: } \\
\mathrm{C}_{\text {bod }}=12.6 \mathrm{pF}, \\
\mathrm{R}_{\text {bod }}=180 \Omega, \\
\text { - Head probe } \\
\text { model: } \\
\mathrm{Rt}=9 \mathrm{M} \Omega \\
\mathrm{Ct}=8 \mathrm{p} \mathrm{F}\end{array}$ \\
\hline
\end{tabular}

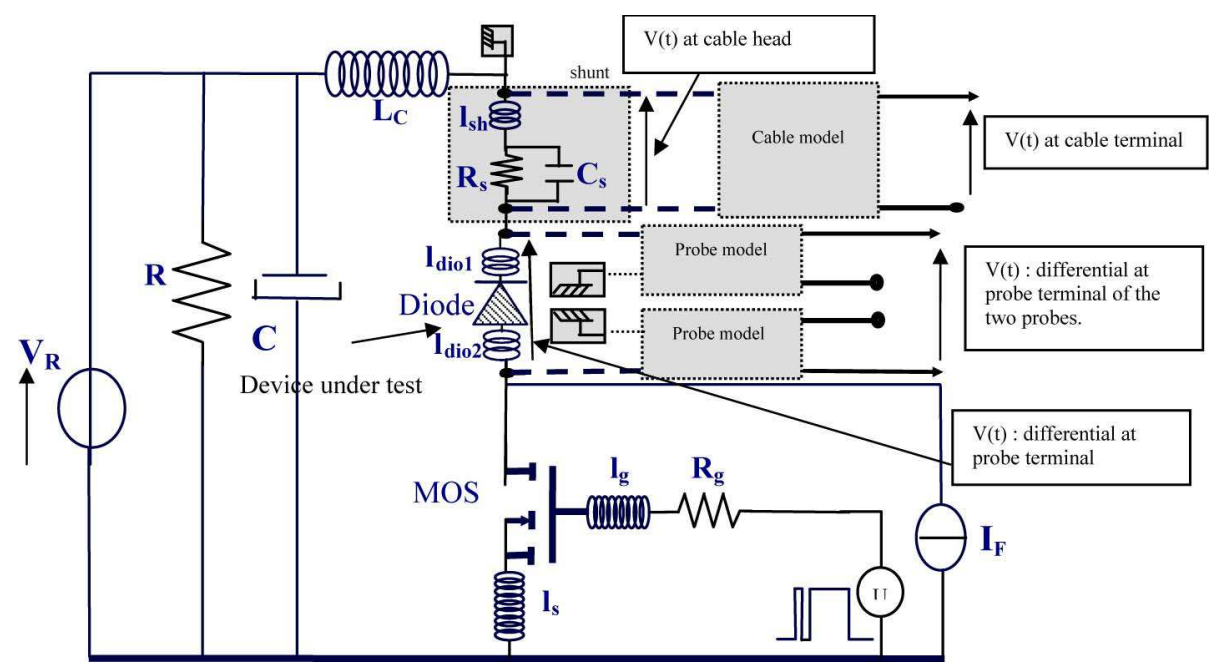

Fig. 10. Used circuit for simulation studies (diode: BYT12PI1000; MOS: IRF740; Lc: equivalent loop wiring; Ldio1 + Ldio2 = Ld: bonding inductor of the diode; shunt model circuit: Ls, Rs, Cs; ls: bonding inductor of the MOSFET; $V_{R}$ : voltage source; $I_{F}$ : current source).

controls the main current most of the time. It is turned off just several microseconds to let the switching cell operate (Fig. 6). Fig. 9 shows the simulation of the diode turnoff transient when power losses are intended to be estimated. The switching cell circuit used for the simulations is pictured in Fig. 10. Accurate modeling of all the components of the switching cell is required. Indeed, modeling of all converter components, including wiring elements, is essential for the accurate measurement of $\mathrm{p}$-i-n diode turnoff behavior. The circuit layout representation may not be simplified to a simple wiring inductance.
The method applied for wire modeling is based on the PEEC method [14]. This is a useful concept in power electronics that enables one to assign an equivalent electrical circuit to each portion of a conductor. This equivalent circuit is an L-R series circuit where all the self-inductances are coupled by mutual inductances. This method has been validated in multiple configurations and for various types of circuit structures [20]. The electrical equivalent circuit is pictured in Fig. 10. The values of self- and mutual inductors are estimated using the software INCA [13]. 

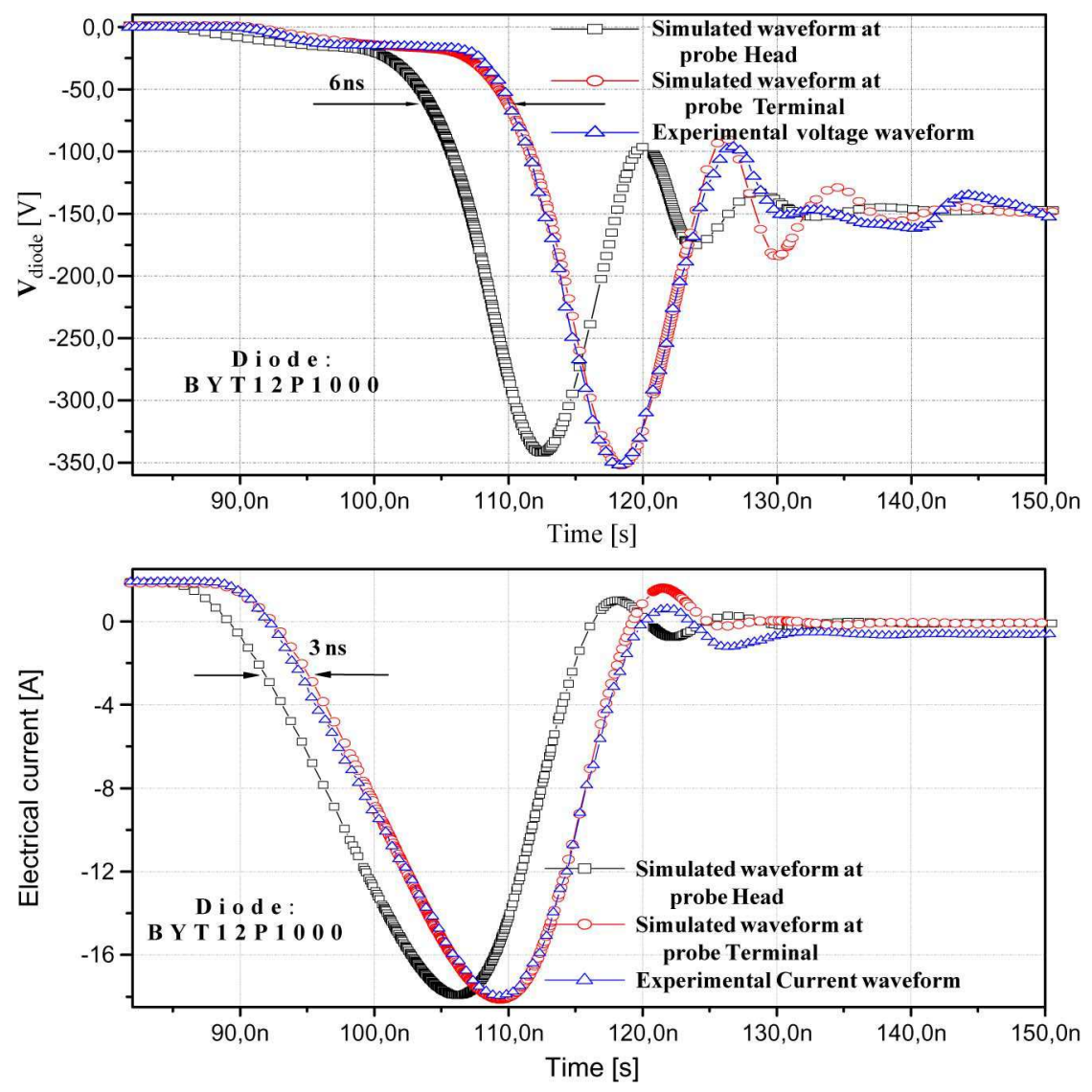

Fig. 11. Comparison between measurements and simulations of the diode (top) voltage and (bottom) current waveforms at the probe head and the probe terminal.

The ISE simulator was used to take a fine simulation of the proposed circuit (Fig. 10). The IGBT is not taken into account in simulations: during MOSFET switching, the IGBT has no influence on the switching cell behavior because of the IGBT wiring outside the printed circuit board cell board. The reference for the measurement, i.e., the oscilloscope mass, was on the side of the dc link. To measure the diode voltage $V_{D}$, two voltage probes in a differential setup were used: one to sense the anode voltage, and the other to sense the voltage cathode. A differential voltage probe based on two Tektronix P6139 products was practically realized, which is now commercialized under the reference Tektronix P6135A.

Accurate high-frequency current measurements may be achieved using a magnetic core transformer or a shunt. Among other techniques, due to high-frequency requirements, a shunt featuring a large bandwidth (dc to $1 \mathrm{GHz}$, type TMS Research SDN_414_025, $0.025 \Omega$ ) was selected. The shunt was connected to a $50-\Omega$ oscilloscope input impedance. The shunt is easy to model because it corresponds to a pure resistor in series with a wiring parasitic inductance. The voltage across the pure resistor was measured by the oscilloscope using a rigid coaxial copper wire of type RG405U. A model of the coaxial wire is needed to provide good models for voltage and current probes. A typical measurement is represented in Fig. 11. Classical waveforms are obtained characterizing hard turnoff of a power p-i-n diode for a reverse voltage $V_{R}=150 \mathrm{~V}$ and for a forward current $I_{F}=2$ A.

\section{Probe Model}

Probe models are required to complete the switching cell model. A classical model of the electrical cable is given by the line ПI-model, including losses in the cable. It corresponds to a sequence of line elements: The distributed resistance of the conductors is represented by a series resistor $R$, an admittance $G$ representing the insulator leakage, an inductor $L$ due to the magnetic field around the wires, self-inductance, and a capacitor $C$ representing the capacitance between the two conductors. Fig. 8 shows the complete model of the voltage probe, including the oscilloscope input impedance effect (Rs, Cs). The voltage probe model comprises a probe head, which is represented by $C_{t}$ and $R_{t}$; a cable, which is represented by the sequence of line elements $(R, L, G, C)$; and a probe body [15], which is represented by $R_{\text {bod }}$ and variable capacitance $C_{\text {bod }}$.

The voltage and current probes have been characterized using an impedance analyzer (HP4194A up to $40 \mathrm{MHz}$ and HP8751 up to $500 \mathrm{MHz}$ ). Fig. 12 compares the simulated and experimental transfer functions of the voltage probe. There is a good agreement between measurements with the impedance analyzer and simulation results using the probe model in Fig. 8. The probe model was validated in the frequency domain, but the linearity of the physical phenomena ruling the probe behavior enables one to assume the validity of the probe model in the time domain. In the cable model, the delay depends on the number $m$ of $(R, G, C, L)$ cells. The delay increases with $m$ but reaches a limit value. 


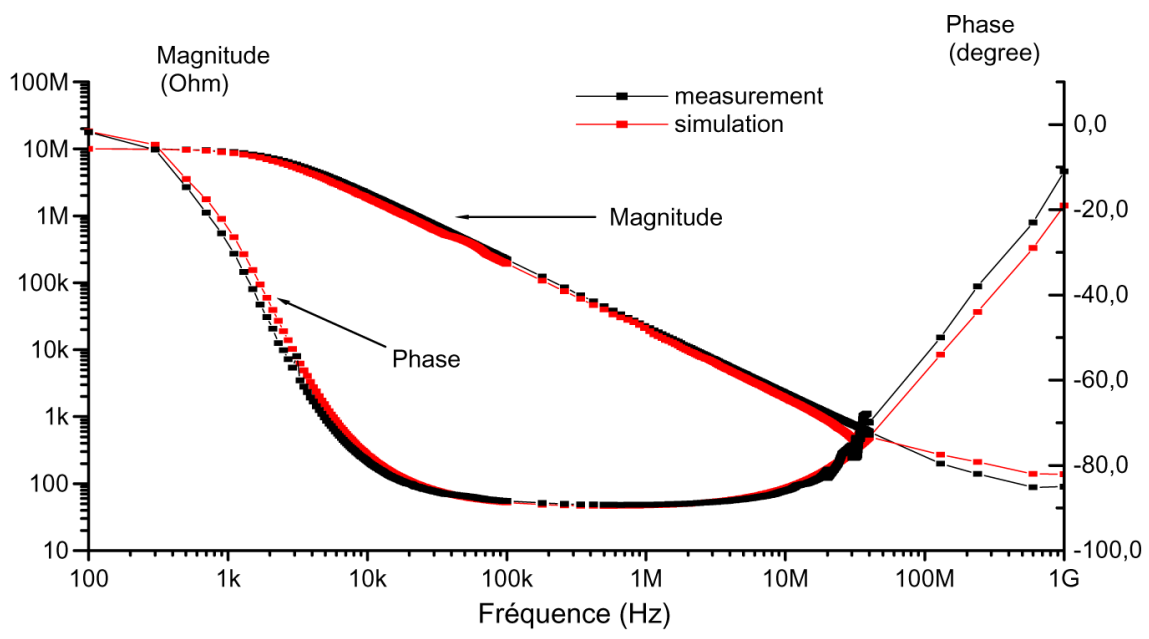

Fig. 12. Simulated and measured impedance of the voltage probe versus frequency.

TABLE IV

Switching Loss Error Versus Applied Voltage $V_{R}$ For No Probe EFFect Compensation and for the Probe Delay Phenomenon. These Errors Are Calculated From the Differences of the Modeled and Simulated Losses at the Probe, Which ARe Deduced to be the True Switching Losses

\begin{tabular}{|l|c|c|c|}
\hline INPUT VOLTAGE VALUE $\left(\mathbf{V}_{\mathbf{R}}\right)$ & $50 \mathrm{~V}$ & $150 \mathrm{~V}$ & $250 \mathrm{~V}$ \\
\hline Error introduced by the probe on switching loss & $27 \%$ & $46 \%$ & $54 \%$ \\
\hline $\begin{array}{l}\text { Introduced errors when delay phenomenon of the probe cable is } \\
\text { taken into account (deskewing process) }\end{array}$ & $6 \%$ & $10 \%$ & $15 \%$ \\
\hline
\end{tabular}

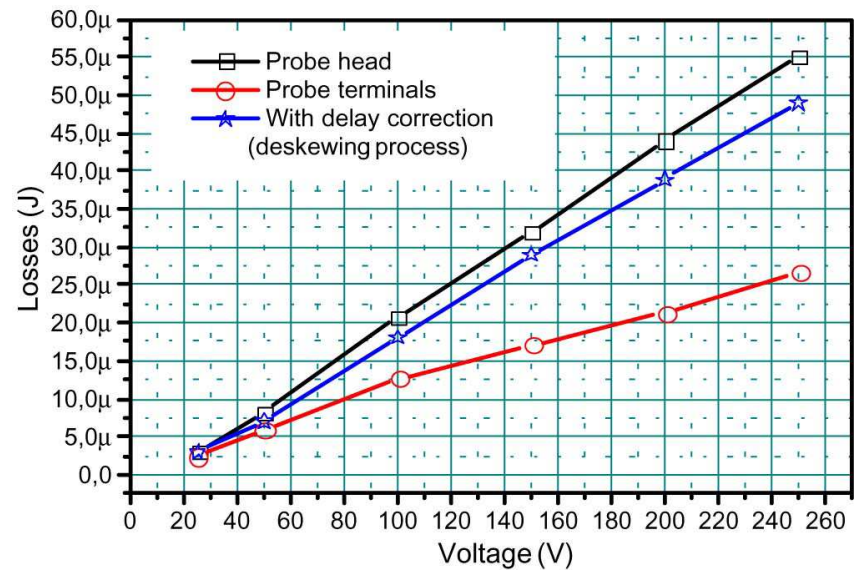

Fig. 13. Diode turnoff loss evaluations versus input voltage obtained by the numerical simulation (diode: BYT12P1000).

According to measurements with the impedance analyzer HP4194A and some parameters found in the datasheet constructor [16], [17], voltage and current probe characteristics are given in Table IV.

The voltage probe model includes a probe head, a cable and, a probe body. Fig. 8 also shows the oscilloscope input impedance model.

The probe and cable models were implemented in ISE, MATLAB, and SABER simulators.

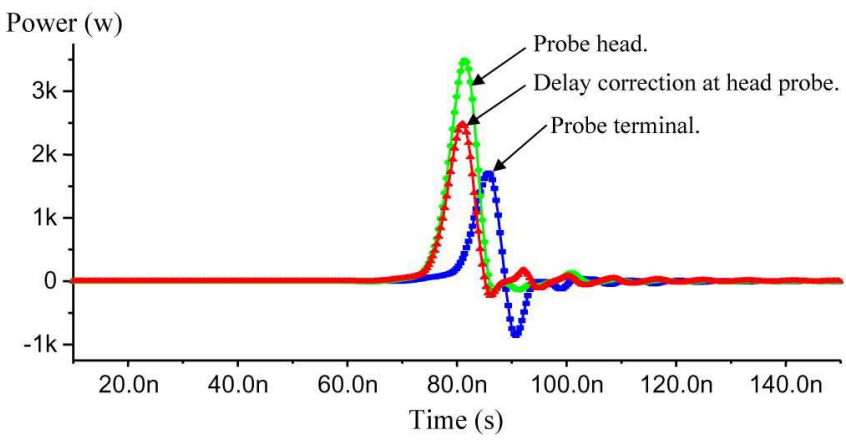

Fig. 14. Diode dissipated power during turnoff obtained by the numerical simulation $\left(V_{R}=150 \mathrm{~V}, I_{F}=2 \mathrm{~A}\right)$.

\section{RESUlts AND Discussion}

Some results are discussed and show that the influence of probes on the measured waveform is not simply "a gain plus a delay." The measurement waveforms represented in Fig. 3 show that a simple cable can introduce an overshot. These variations influence the estimation of the energy losses during device transients.

This section presented the test bench considered for analyzing the probe behavior.

Comparisons of measurements and simulations for voltage and current waveforms before and after the probes are considered. Fig. 11 compares simulation results to experimental results for diode current and voltage waveforms during turnoff. 


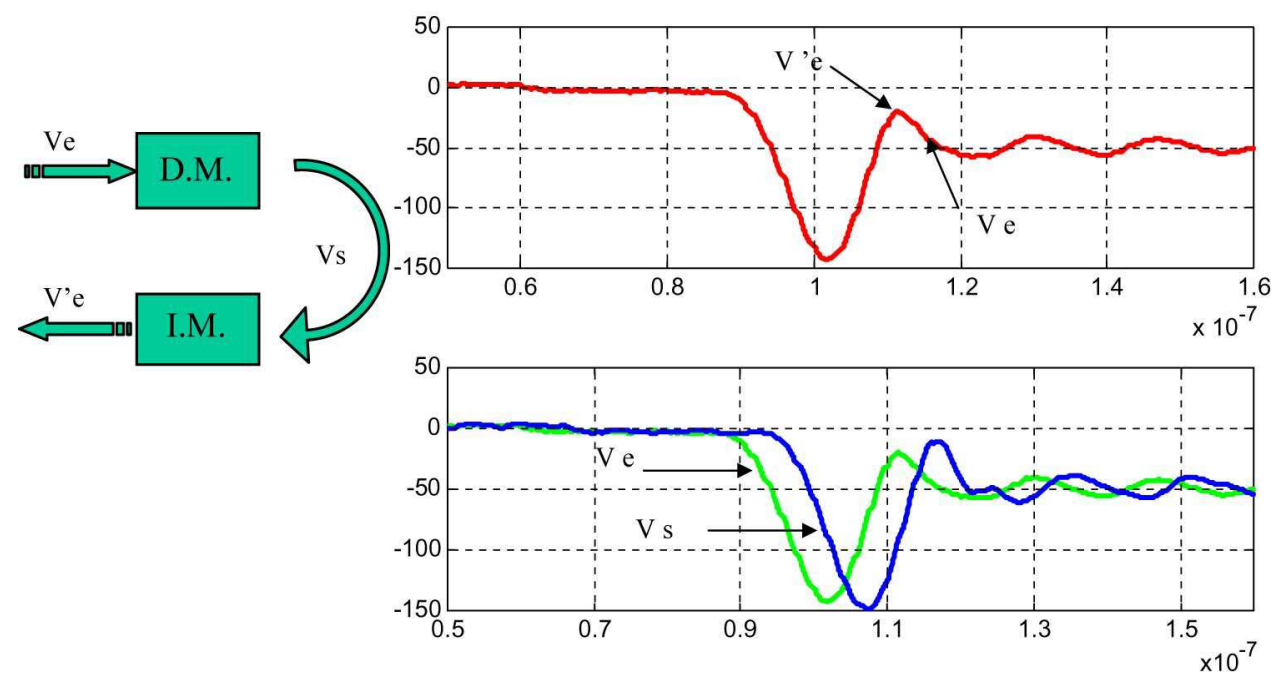

Fig. 15. Inverse waveform ( $\left.\mathrm{V}^{\prime} \mathrm{e}\right)$ obtained by the inverse probe models (I.M.)

Simulations compute waveforms at the probe heads and at the probe terminals. Then, comparisons with measurements of voltage and current waveforms are possible. Simulation waveforms at the probe output, i.e., the oscilloscope input, are in good agreement with experimental data and support the accuracy of our models.

Fig. 11 shows that the voltage probes introduce overshoots and delays in fast transient responses. The delays may be compensated with an offset; however, the overshoots are obviously difficult to correct.

Fig. 13 represents the power loss estimation versus the reverse voltage applied to the diode during switching. The power losses are estimated from simulated waveforms at the probe head and probe terminals, respectively. Power is also estimated when voltage probe terminal waveforms are corrected from the cable propagation delay. It may be considered that the "genuine" power losses are estimated at the input of the probe model (probe head). Considering the current and voltage waveforms at the probe terminals and integrating the waveform product introduce an important error: this is the classical method from the experimental point of view. Fig. 13 shows that this latter basic method introduces $30 \%$ (at $V_{R}=50 \mathrm{~V}$ ) of discrepancy with regard to the "genuine" power losses at the probe head with increasing error with turnoff hardness. In addition, correcting with time delay between the voltage and current waveforms reduces the error to $6 \%$ at $V_{R}=50 \mathrm{~V}$ and $15 \%$ at $V_{R}=250 \mathrm{~V}$. In general, the error increases with turnoff hardness. It is dependent on the different types of semiconductor components, the reverse voltage, the forward current, and the probe devices.

To obtain the real voltage and current waveforms of the devices, an inverse model of the probe should be used. In fact, when the measured electrical waveforms (from the oscilloscope) are applied at the input of the inverse model, the real evolution of these waveforms can be calculated.

Fig. 14 presents the estimation of the diode energy loss during turnoff $\left(V_{R}=150 \mathrm{~V}, I_{F}=2 \mathrm{~A}\right)$. The simulation results picture the energy loss with and without a delay correction.

A global correction is necessary, and cable inverse models are a suitable approach for such a task. For example, the "traveling-wave" model considers the wave equations inside the cable. No details are presented in this paper. The reverse model then comes as

$$
\begin{aligned}
V_{e}(t)= & V_{s}(t+\tau)+V_{s}(t-\tau) \\
& +Z \cdot\left[I_{s}(t+\tau)-I_{s}(t-\tau)\right] \\
i_{s}(t)= & \left(V_{e}(t-\tau)-V_{s}(t)\right) \cdot Y_{Z}+i_{e}(t-\tau) \\
i_{e}(t)= & \left(V_{e}(t)-V_{s}(t-\tau)\right) \cdot Y_{Z}+i_{s}(t-\tau)
\end{aligned}
$$

$Y_{Z}=1 / Z$, where $Z=\sqrt{L / C}$ is the characteristic impedance of the line, and $v=1 / \sqrt{L C}$ is the phase velocity. In addition. $\tau=d / \nu$ is the travel time of the wave to get from one side of the line portion $(e)$ to the other side $(s)$.

Fig. 15 presents the voltage probe inverse-model response (V/e) to a voltage waveform of a p-i-n diode during turnoff.

The initial signal Ve is applied to the direct model (D.M.), the output voltage Vs is applied to the inverse model (I.M.), and the output voltage Vıe is similar to the initial voltage Ve.

\section{CONCLUSION}

In this paper, we have shown that it is important to model the current and voltage probes to compare simulation and experimental waveforms in the case of fast measurement switching phases. Moreover, the influence of a probe is not simply a gain plus a delay. The introduction of a simple delay correction on electrical waveforms is not sufficient to achieve an accurate estimation of power losses, particularly for fast switching devices. If the equivalent capacitance value of the DUT is of the same order of magnitude as the input capacitance value of the probe, the distortion introduced by the probes is not negligible.

Voltage and current waveforms are often the input data used to improve device model parameter extraction algorithms. Indeed, classical identification procedures are based on the discrepancies between experimental and simulation results. The precision of the extracted parameter values depends on the accuracy of the probe model.

A probe reverse model may be considered and applied to experimental results to produce a correction of the measured waveforms. Then, the power loss estimation will be more accurate, particularly in the case of fast semiconductor devices. 


\section{REFERENCES}

[1] Y. Lembeye, "Métrologie de La Commutation de Puissance Rapide. Contribution à la Caractérisation et à la Recherche d'un Model d'IGBT," Ph.D. dissertation, I.N.P. de Grenoble, Grenoble, France, 1997.

[2] R. B. Marks, "A multiline method of network analyzer calibration," IEEE Trans. Microw. Theory Tech., vol. 39, no. 7, pp. 1205-1215, Jul. 1991.

[3] C. J. Wei, Y. A. Tkachenko, J. C. M. Hwang, K. E. Smith, and A. H. Peake, "Internal-node waveform probing of MMIC power amplifiers," in Proc. IEEE Microw. Millimeter Wave Monolithic Circuits Symp., 1995, pp. 127-130.

[4] J. C. M. Hwang, "Internal waveform probing of MMIC power amplifiers," in Proc. 2nd Int. Conf. Microw. Millimeter Wave Technol., 2000, pp. 638-641.

[5] ABC's of Probe, Probes and Effects of Bandwidth on Transient Information. Application notes. [Online]. Available: www.tek.com

[6] Using Real Time Oscilloscopes to Make Power Electronics Measurement. Application notes. [Online]. Available: www.tek.com

[7] Effects of bandwidth on transient information, Accurate instantaneous power measurement, Probe and probing. Application notes. [Online]. Available: www.lecroy.com

[8] 4 Step for Making Better Power Measurements (AN64-4c). [Online]. Available: www.agilent.com

[9] T\&M Research Products Series SDN-414. [Online]. Available: www.tandmresearch.com

[10] The Effect of Probe Input Capacitance on Measurement Accuracy and FAQ Probes. Application notes. [Online]. Available: www.tek.com

[11] ISE User's Guide, ISE, Zurich, Switzerland, 1995-1999.

[12] G. Massobrio and P. Antognetti, Semiconductor Device Modeling With SPICE, 2nd ed. New York: McGraw-Hill, 1988.

[13] INCA User's Guide, Cedrat, Grenoble, France, 1995.

[14] A. E. Ruehli, "Inductance calculations in a complex integrated circuit environment," IBM J. Res. Develop., vol. 16, no. 5, pp. 470-481, Sep. 1972.

[15] Tektronix, The A-B-C's of Probes and Probes and Probing, Zurich, Switzerland, Application Notes, 20. DESSIS-ISE, User's guides 19951999. [Online]. Available: www.tek.com

[16] J. M. Griffith and R. Lebender, "Electrical characteristics of ribbon-based probe cables," in Proc. IEEE Ultrasonics Symp., 1999, pp. 1085-1090.

[17] J. Griffth, P. Reynolds, D. Powell, G. Wojeik, R. Richards, and P. Wynn, "Cable parameters and acoustic probe performance," in Proc. IEEE Ultrasonics Symp., 2000, pp. 1055-1059.

[18] H. W. Johnson, High Speed Signal Propagation: Advanced Black Magic. Englewood Cliffs, NJ: Prentice-Hall, 2003.

[19] C. Hoer and C. Love, "Exact inductance equations for rectangular conductors with applications to more complicated geometries," J. Res. Nat. Bur. Stand. C-Engineering and Instrumentation, vol. 69C, no. 2, pp. 127-137, Apr.-Jun. 1965.

[20] H. Garrab, B. Allard, H. Morel, K. Ammous, S. Ghedira, A. Amimi, K. Besbes, and J.-M. Guichon, "On the extraction of PiN diode design parameters for validation of integrated power converter design," IEEE Trans. Power Electron., vol. 20, no. 3, pp. 660-670, May 2005.

[21] D. F. Williams and R. B. Marks, "Transmission line capacitance measurement," IEEE Microw. Guided Wave Lett., vol. 1, no. 9, pp. 243-245, Sep. 1991.



Kaiçar Ammous was born in Sfax, Tunisia, in 1975. He received the M.S. degree in electrical engineering from the Ecole Nationale d'Ingénieurs de Sfax (ENIS), Sfax, Tunisia, in 1998 and the Ph.D. degree in electrical engineering from the Institut National des Sciences Appliquées (INSA) de Lyon, Villeurbanne, France, in 2002.

He is currently with Groupe de Recherche, Power Electronic Group, Département de Génie Electrique, ENIS. His current research interests are power semiconductor device modeling, electrothermal modelization, average modeling, and power system simulations and designs

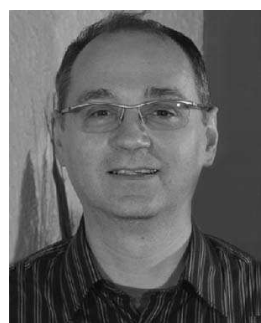

Hervé Morel (S'07) was born in Reims, France, in 1959. He received the Engineer and Ph.D. degrees from the Ecole Centrale de Lyon, Ecully, France, in 1982 and 1984, respectively.

In 1985, he joined the CNRS as an Associated Scientist. He is currently a Senior Scientist with the Laboratoire Ampère, Institut National des Sciences Appliquées (INSA) de Lyon, Villeurbanne, France. His research area includes power semiconductor device characterization and modeling, CAE of power electronic system integration, and multiphysics modeling based on bond graphs. He is particularly involved in the design of hightemperature power electronics for the More Electric Aircraft. He is the Manager of the French Academic Network on Electrical Engineering (SEEDS).

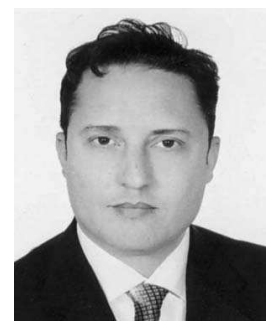

Anis Ammous was born in Sfax, Tunisia, in 1970. He received the electrical engineering degree from the Ecole Nationale d'Ingénieurs de Sfax (ENIS), Sfax, in 1994, the Ph.D. degree in electrical engineering from the Institut National des Sciences Appliquées (INSA) de Lyon, Villeurbanne, France, in 1998, and the HDR degree in electrical engineering from ENIS in 2003.

$\mathrm{He}$ is currently a Professor with ENIS, where he is responsible of the Power Electronic Group (PEG). $\mathrm{He}$ is the author or coauthor of more than 50 scientific papers. He is the holder of two patents. His current research interests are power semiconductor device modeling, electrothermal modelization, and power system simulations and designs. Among his works is the optimization of power converter topologies in renewable energy applications. 